\title{
Guia de relações multiespécies na Baía de Florianópolis - SC
}

\author{
IVAN TADEU GOMES DE OLIVEIRA \\ Universidade Federal de Santa Catarina | Santa Catarina, SC, Brasil \\ ivan.gomes@protonmail.com
}

DOI 10.11606/issn.2316-9133.v30i1pe179745

Este ensaio gráfico é resultado de vasta pesquisa acerca da frutífera associação entre antropologia e desenho. Mas mesmo antes do trabalho junto a teorias que ajudaram a situar o desenho no trabalho etnográfico, minhas mãos sempre me levaram a mobilizar as linhas desenhadas como forma de conhecer o mundo e manifestar as sínteses das minhas experiências. Muito embora de maneira intermitente, expressões gráficas apareciam aqui e ali ao longo de minha trajetória escolar, mesmo na graduação em Ciências Sociais, e o papel dos mestreprofessores que motivaram essa prática foi também fundamental.

Mas foi ao longo da etnografia e das pesquisas para a dissertação, com incentivo do meu orientador prof. Dr. Rafael Devos, que a coordenação entre desenho e antropologia passou a ganhar mais corpo e reflexão. O maior desafio desse projeto diz respeito à mobilização do corpo para empreender os movimentos e a disciplina necessários para compor os desenhos. Tendo a escrita como prática central da formação escolar, a resistência em ficar diante de uma prancheta de desenho foi um obstáculo que constantemente houvera que ser transposto. Não apenas diante de uma prancheta, como o próprio desenho no caderno de campo durante as incursões à paisagem. Mesmo inclinado a desenhar, e ter certa familiaridade com a habilidade, não posso deixar de registrar como escrever demandou menos esforço corporal do que desenhar.

Mais do que cumprir com o compromisso que, em meu íntimo, firmei com o projeto proposto, eu queria me esforçar em, aos poucos, atravessar essas barreiras corporais e exercitar o desenho não apenas como maneira de representar a paisagem analisada, mas, mais do que isso, para ajudar a abrir canais perceptivos para as potencialidades que o desenhar tinham a oferecer para minha formação como antropólogo e, antes disso, como habitante da paisagem. Além disso, foi criando mais corpo a sensação de que a linguagem a partir dos desenhos propiciam maneiras bastante particulares de tratamento das experiências etnográficas, e eu ansiava em me arriscar e experimentar essas experiências. 
Em meu auxílio, sempre tive a companhia de amigas/os antropólogas/os com papeis diversos: desde inspirar teórica e graficamente, até motivar nos momentos de insegurança exagerada. Em especial não posso deixar de citar Aina Azevedo (2016a; 2016b) e seu amplo trabalho com antropologia e desenho, em especial o magnífico Weathering, em parceria com Sara Schroer (Azevedo e Schroer, 2016) - um ensaio gráfico que me abriu as portas das possibilidades e potencialidades das coordenações entre antropologia e desenho. Weathering é um ensaio gráfico que trata de um retalho ecológico em que se desenvolve a interação mais que humana dentro da prática da falcoaria. A fim de descrever os diversos elementos - humanos e não humanos - que compõem a falcoaria, o desenho nos ajuda a perceber diversas dinâmicas de maneira nítida, ilustrativa e muito bela.

Outro antropólogo que colaborou neste projeto foi Tim Ingold (2015) em suas reflexões sobre algumas características que orbitam o desenho, o desenhar e as potencialidades quando em composição com a etnografia. Em especial destaco o diálogo que Tim Ingold realiza com o historiados da arte Norman Bryson, ensaiando comparações entre a pintura a óleo ocidental e o desenho. Ingold argumenta que pintura a óleo preenche totalmente a tela, que não há espaço sem preenchimento. $\mathrm{Na}$ tarefa de representar seu objeto, o pintor cobre com grossa camada de tinta não apenas o vazio, como os traços dos esboços que serviram de guia no processo de composição das formas e do trabalho final. Não era por essa trilha que eu pretendia seguir, tendo em vista que minha sensibilidade diante da paisagem percebia muitas linhas em constante emaranhamento, tecendo o ambiente (Ingold, 2015). Linhas que se tocam, se cruzam, mas não definem nem estacionam. Como os desenhos.

Desenhos, do ponto de vista de Ingold e Bryson - e do meu também -, não pretendem completar a tela. Linhas são levadas a passear (Klee apud Ingold, 2015) e, por repetição e leve (ou pesada) tessitura, deixam transparecer vazios no papel, uma vez que não têm por obrigação obediência à "lei do por toda parte", mantendo à mostra o processo de composição, tornando a superfície do desenho uma reserva de possibilidades (Ingold, 2015). Não significa que a natureza inconclusa do desenho não seja capaz de contar histórias sobre o campo: o emaranhado de linhas, apesar de não conhecer uma conclusão final, possui a capacidade de se destacar e produzir formas distinguíveis na superfície em que se deita o desenho. Da mesma forma, a paisagem sob perspectiva antropológica nos convida, assim como o desenho, a compor etnografias que se inspirem em seu aspecto processual, aberto, antitotalizante e inconclusivo (Ingold, 2015).

A (re)aproximação do desenho com antropologia - ou o desenho como método etnográfico - inspirou desafios que ultrapassaram minha habilidade motora fina. Afinal, não se trata aqui de atribuir a qualidade do método à qualidade do traço (Kuschnir, 2012). Nesse sentido, ao longo da pesquisa, foram arriscadas algumas experimentações com caderno e caneta nanquim no colo e nas mãos, com o corpo sentado na cadeira de praia estirada na passarela da ponte Pedro Ivo Campos, em Florianópolis - SC, deixando o olhar se demorar no espaço que 
pretendia etnografar. Disso saíram alguns dos desenhos espalhados neste ensaio. Era o aquecimento. Foi o bastante para perceber no corpo a distinção temporal em relação à métodos como a filmagem ou a fotografia.

Outro destaque digno de nota são as interações que o desenho e o desenhar podem provocar entre antropólogo/a e interlocutor/a. Permanecer sentado - ou em pé, ou caminhando, como for - com caderno e caneta no colo e nas mãos atraiu atenção desejada para começar a desenvolver relações com os interlocutores. Curiosidade, admiração e surpresa se mostraram caminhos para a aproximação entre nós.

Este ensaio gráfico buscou diálogo com outros campos e saberes, como a ecologia, a biologia, a oceanografia, a teoria literária, a literatura e a arquitetura. Imaginação é potência. $O$ "inreal" borra o limite entre real e irreal. A especulação pode auxiliar antropólogos e antropólogas adentrar potencialidades da paisagem. O fantástico trabalho da arquiteta Ângela León (2018) em diálogo com as ideias dos romancistas Daniel Galera (2019) e José Saer (2009), além das reflexões de Alexandre Nodari (2015) resultaram em uma pequena epifania: inscrever, por meio de desenhos, elementos da paisagem que faço campo com base nas imaginações dos interlocutores que a habitam. Conversar com pescadores, ciclistas e peregrinos que circulam (ou não) pela passarela, pelas margens e pela baía de Florianópolis - SC, pedindo que imaginem, descrevam e projetem melhorias ou idealizações da paisagem de tal forma a tornar sua prática mais prazerosa, alegre, harmônica e convidativa - ou seja, pedir que façam o mapeamento do ambiente com base em sua forma de percebê-lo e projetá-lo.

Fazer um esforço ainda por uma antropologia que se atente à "outridade significante", como propôs Donna Haraway (2003). Um Outro que se comunica por outros canais que não a linguagem verbal - procurar entender também as perspectivas e projetos de fazer mundo dos habitantes não humanos da paisagem. A partir de suas narrativas, elaborar croquis, projetos, desenhos fantásticos - inspirado pelos desenhos de Ângela León - na intenção de que as respostas possam me dizer muito sobre a paisagem, o ambiente e as habitabilidades e socialidades de seus habitantes.

Tomado por essa soma de inspirações, junto com as demais pesquisas e incursões a campo realizadas ao longo da pesquisa, entre 2019 e 2020, compus o ensaio gráfico que segue. Assim como o desenho de que fala Tim Ingold, esse é um ensaio processual, aberto, antitotalizante e inconclusivo. $\mathrm{O}$ fim não é bem um fim. A paisagem permanece em devir quando viramos nossas costas e nos dirigimos para casa. O que ficam são as histórias que tentei contar a partir do desenho, e que espero que possam imprimir em quem tiver contato com elas novas percepções sobre a paisagem da baía de Florianópolis, suas dinâmicas, seus habitantes e sua assembleia mais que humana.

\footnotetext{
${ }^{1}$ Inreal é empregado aqui a partir do uso que lhe foi dado por Clarice Lispector, como notou Nodari (2015: 82).
} 


\section{Referências bibliográficas}

AZEVEDO, Aina. 2016a. Desenho e antropologia: recuperação histórica e momento atual.

Cadernos de Arte e Antropologia, v. 5, n. 2. p.15-32. DOI https://doi.org/10.4000/cadernosaa.1096

AZEVEDO, Aina. 2016b. Um convite à antropologia desenhada. METAgrahias: metalinguagem e outras figuras, v. 1, n. 1. P.194-208. DOI https://doi.org/10.26512/mgraph.v1i1.50

AZEVEDO, Aina; SCHROER, Sara Asu. 2016. Weathering: a graphic essay. Vibrant, v. 13,

HARAWAY, Donna. 2003. The Companion species manifesto: dogs, people and significant otherness. Chicago: Prickly Paradigm Press.

INGOLD, Tim. 2015. Estar vivo: ensaios sobre movimento, conhecimento e descrição. Trad. Fábio Creder. Petrópolis: Vozes.

KUSCHNIR, Karina. 2012. Desenhando cidades. Sociologia \& Antropologia. v. 02, n. 04: p. 295314.

DOI: https://doi.org/10.1590/2238-38752012v2413

LEÓN, Ángela. 2018. Guia Fantástico de São Paulo. 2a edição. São Paulo: Lote 42.

NODARI, Alexandre. A literatura como antropologia especulativa. Revista da ANPOLL (Online), v. 1, p. 75-85, 2015.

SAER, Juan José. O conceito de ficção. Tradução de Joca Wolff. Sopro, 15, p. 1-4, 2009.

TSING, Anna. The mushroom at the end of the world: on the possibility of life in capitalist ruins. Reino Unido: Princeton University Press.

TSING, Anna. Viver nas ruinas: paisagens multiespécies no Antropoceno. Brasília: IEB Mil Folhas, 2019.

sobre o autor

\section{Ivan Tadeu Gomes de Oliveira}

Mestre em Antropologia Social, bacharel em Ciências Sociais, ambos pela Universidade Federal de Santa Catarina (UFSC). Também é Técnico Administrativo em Educação na mesma instituição.

Contribuição de Autoria: Não se Aplica

Financiamento: A pesquisa não contou com financiamento público.

Recebido em 10/12/2020

Aceito para publicação em 08/06/2021 
GOMES DE OLIVEIRA | Guia de relações multiespécies na Baía de Florianópolis - SC | 5

Assembleia mais que humana

na baía da llha de

Santa Catanina

"Assembleias de paisagems surgem da justaposicáo de variados modos de fazer mundos; nenhuma cosmologia singular pode ordemar uma 


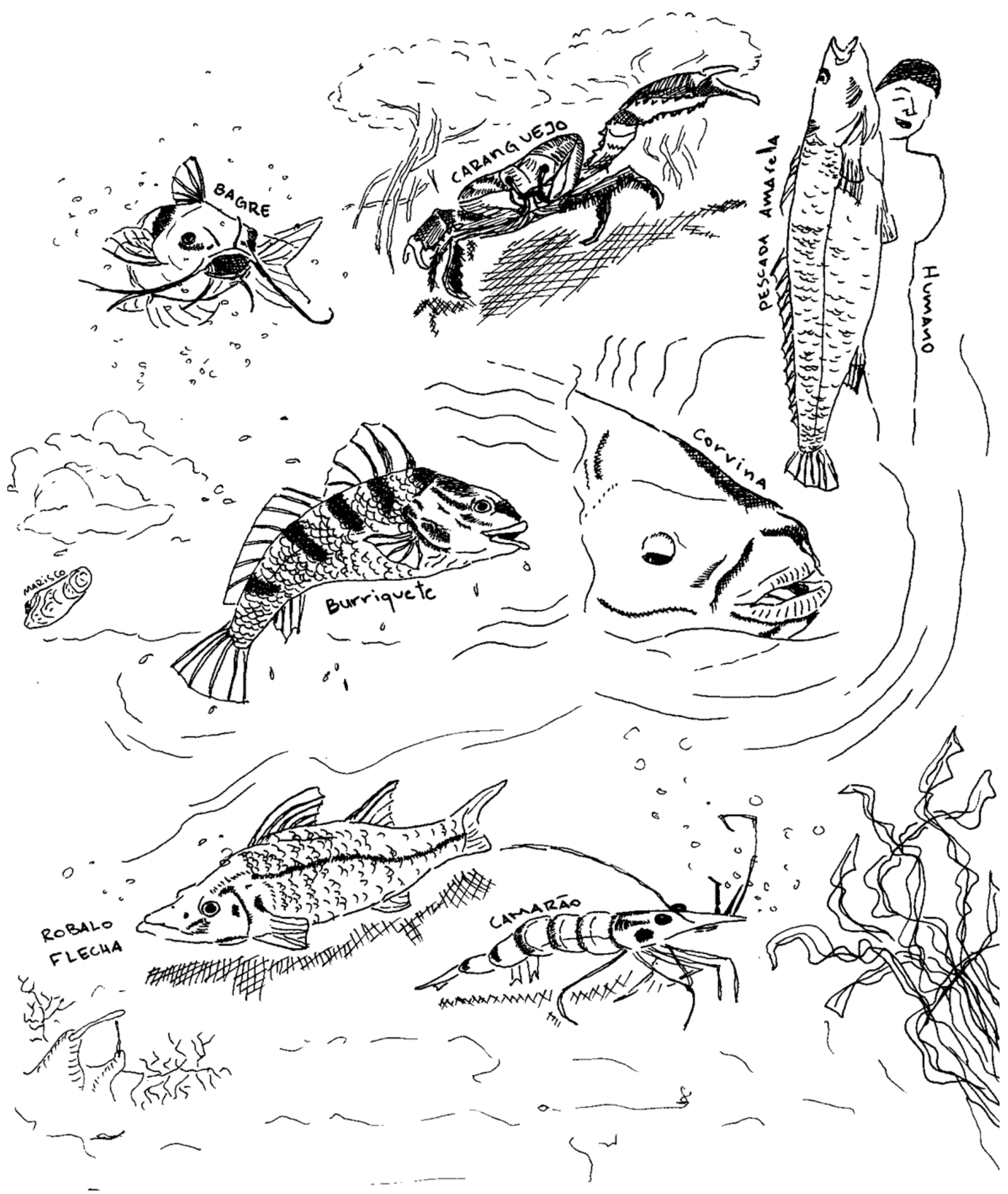



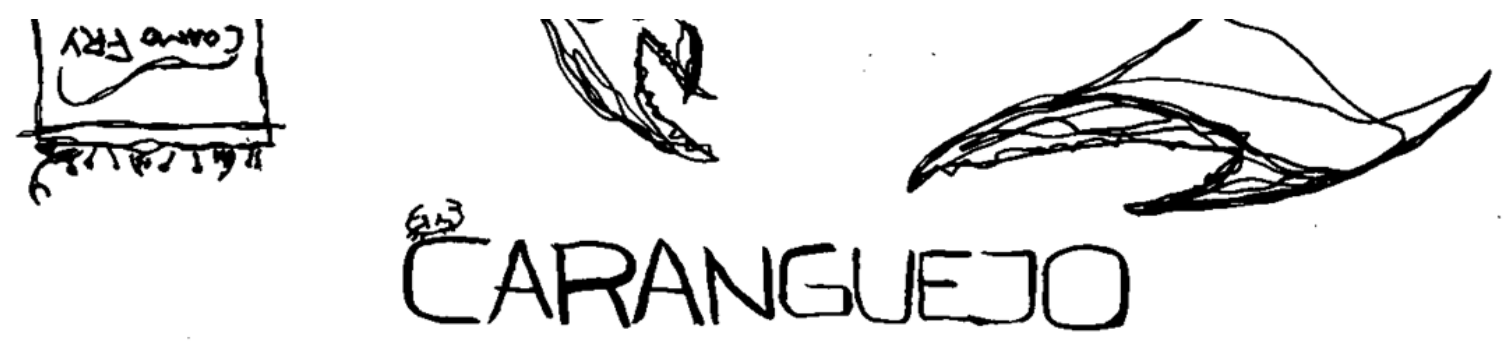

SÁO CRUSTÁCEOS HABITANTES DE MAN-

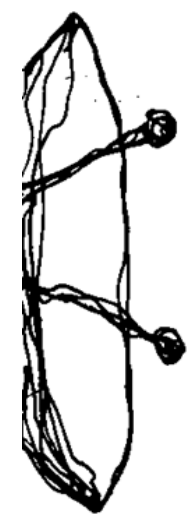

GUEZAIS. A PERCEPCAO HUMANA, SEUS MOVIMENTOS SADO LENTOS E AR RASTADOS, MAS QUE NAO HAJA DESCUIDO: SUAS GARRAS SE FECHAM COM SURPREENDENTE VELOCIDADE AO MENOR SINAL DE AMEACA. ESTRANHAM NOSSO MODO DE ANDAR: "COM PRESSA E PRA FRENTE NÁO SE HABITA LUGAR ALGUM", DIZEM PODEM SER AVISTADOS VISITANDO a passarela Da ponte pedro ivo campos NA COMPANHIA DE PESCADORES. LEVADOS DO MANGUE para a casa do pescador, sáo TRATADOS a PÁO-DE-LO': "TIRAMPS A SORTE GRANDE", COMEMORAM, iGNOTANTES SOBRE SEU FUTUro: virarem isca de burriquete.
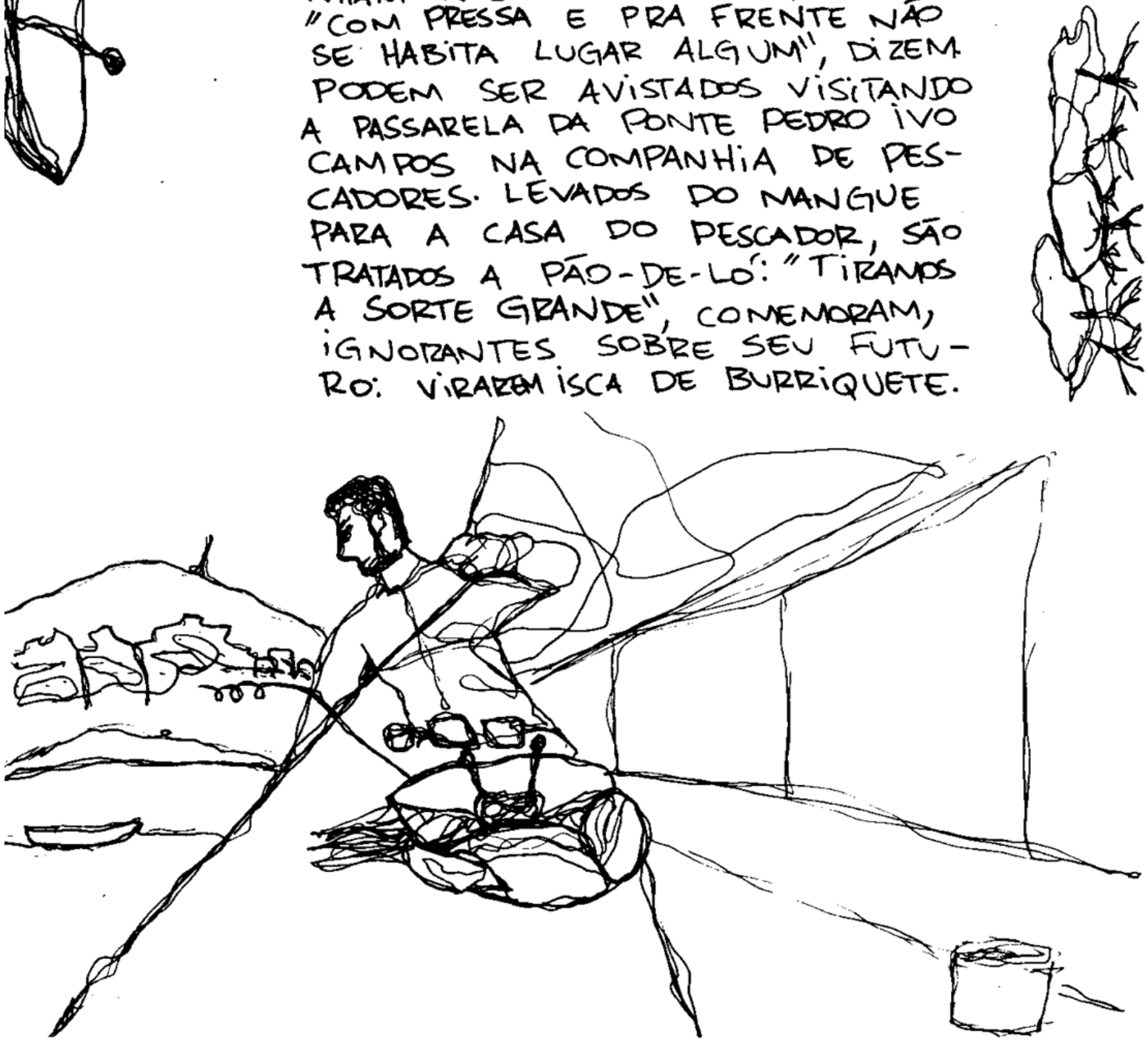


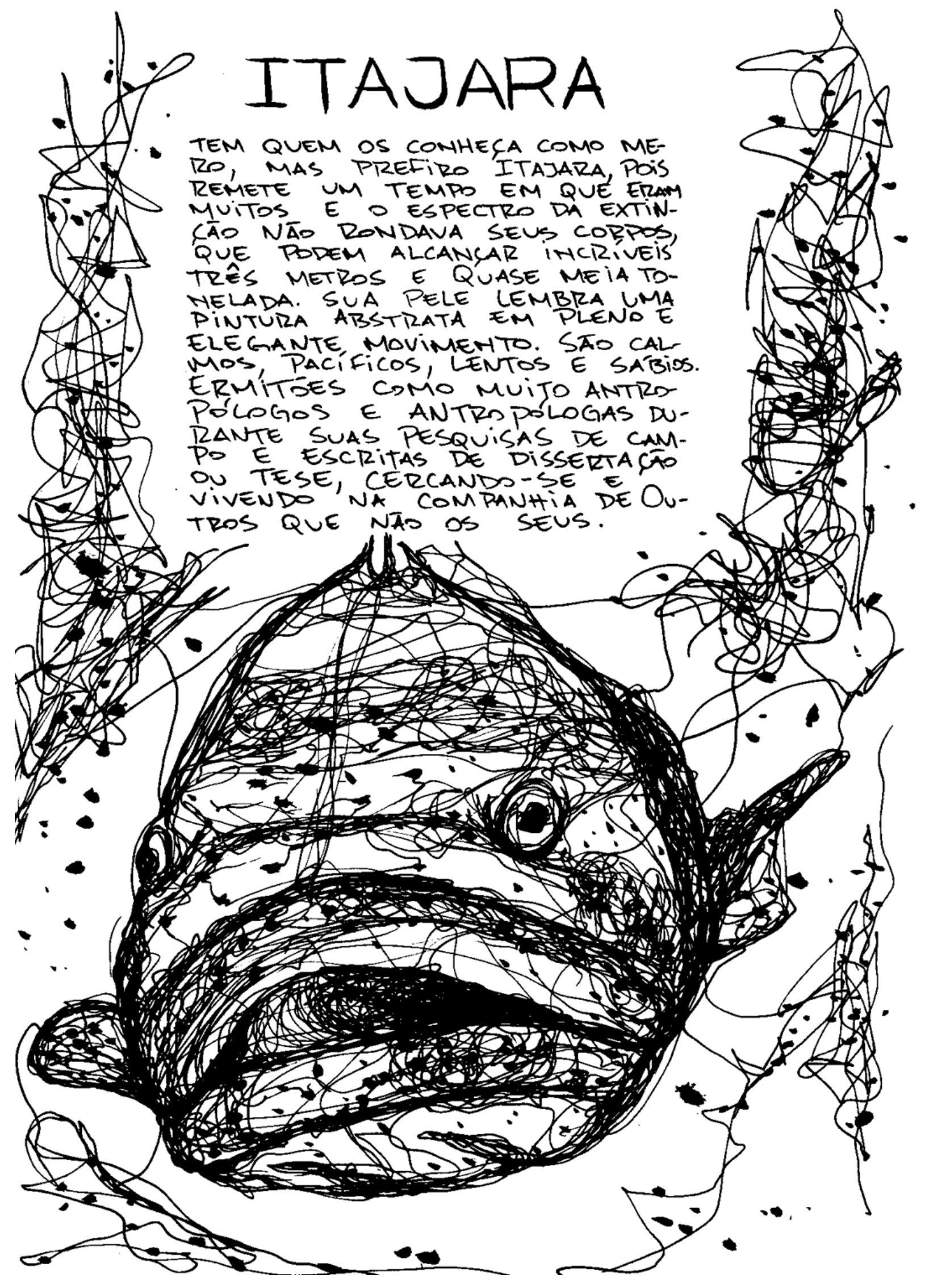

Cadernos de Campo (São Paulo, online) | vol. 30, n. 1 | p.1-18 | USP 2021 


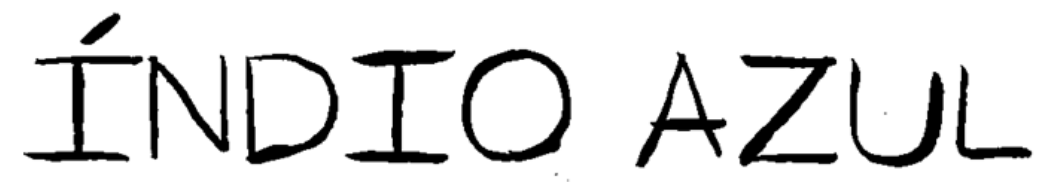
TATUADO NA PELE DA PONTE, O ta plástico de rua cranio, HABITANDO AS CERCANIAS DO CANAL CENTRAL dE FLORIANópolis. DESDE MEADOS DA DÉCADA DE ZOIO. DISPGE DE INCONTÁveIS - PDSTO EFEMEROS - PARENTES ESPALHADOS EM EQUIDAMENTOS URBANOS E ARQUITETONICOS MUNDO AFOUA. TACITURNO E RESER. VADO, VIVE EM COMPANHIA DOS CAMALESES DO RIZO DAS FONTES ESTILOSAS DO VEJAM E MUITAS OUTRAS ENTIDADES PIGMENTADAS. Quando baixa soberano vento SUL, 0 IndiO AZUL E' DOS POUKOS habitantes do canal vistos por Ali, apesar de claramente senTir a condicão de, SEMi nu. Há BaATOS EM QUE O ÍNDIO AZUL ATUA REPELINDO FORCAS DE NATUREza reDrESSORA que SE alimenTAM DE ENERGIAS CRIATIVAS, E QUE NUNCA ANTES O INDID AZUL trabalHo tanto como no último par dE aNo...

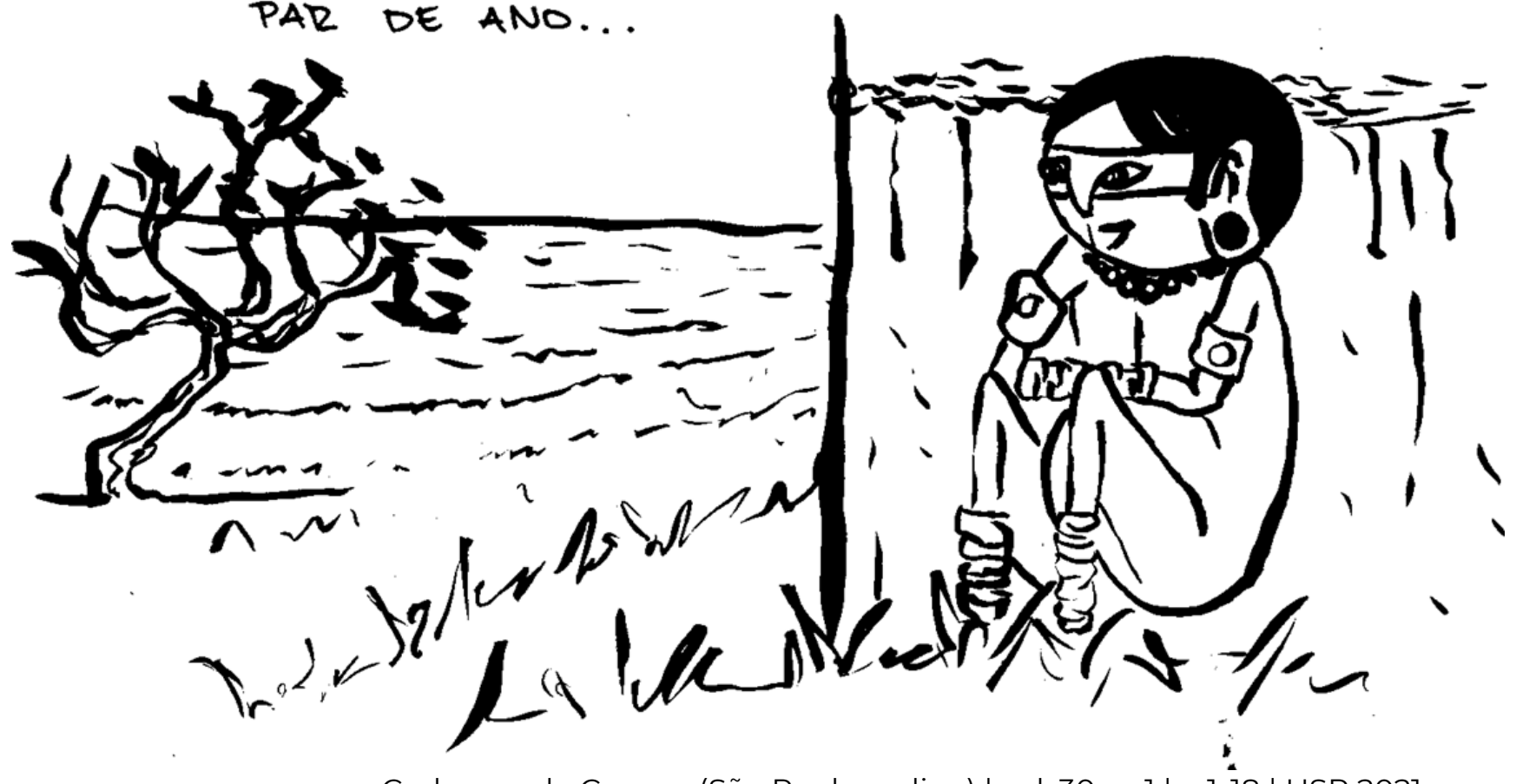

Cadernos de Campo (São Paulo, online) | vol. 30, n. 1 | p.1-18 | USP 2021 
GOMES DE OLIVEIRA | Guia de relações multiespécies na Baía de Florianópolis - SC | 10

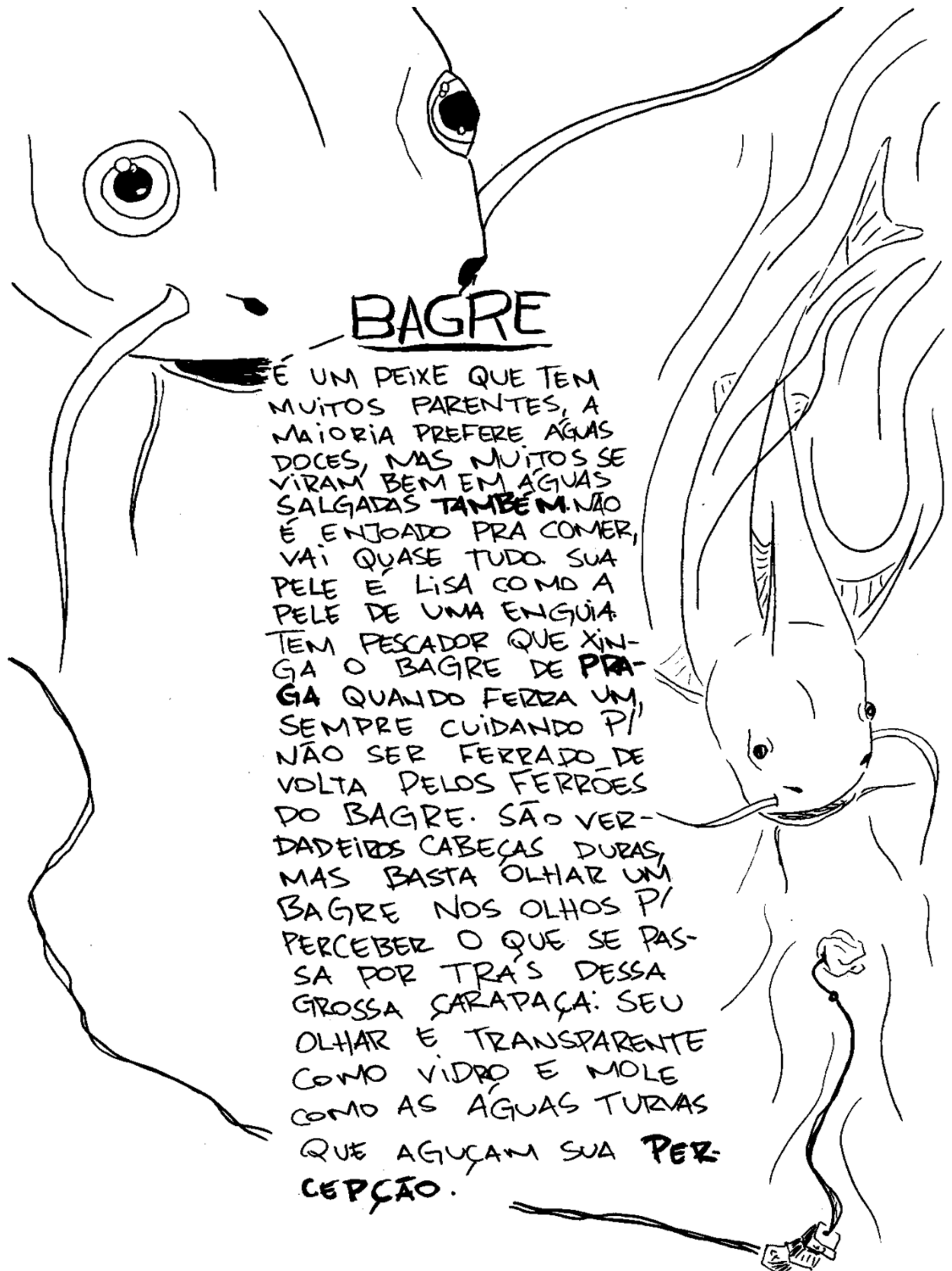


GOMES DE OLIVEIRA | Guia de relações multiespécies na Baía de Florianópolis - SC | 11

Arte de pesca com

Tabuinha e Ferrinho
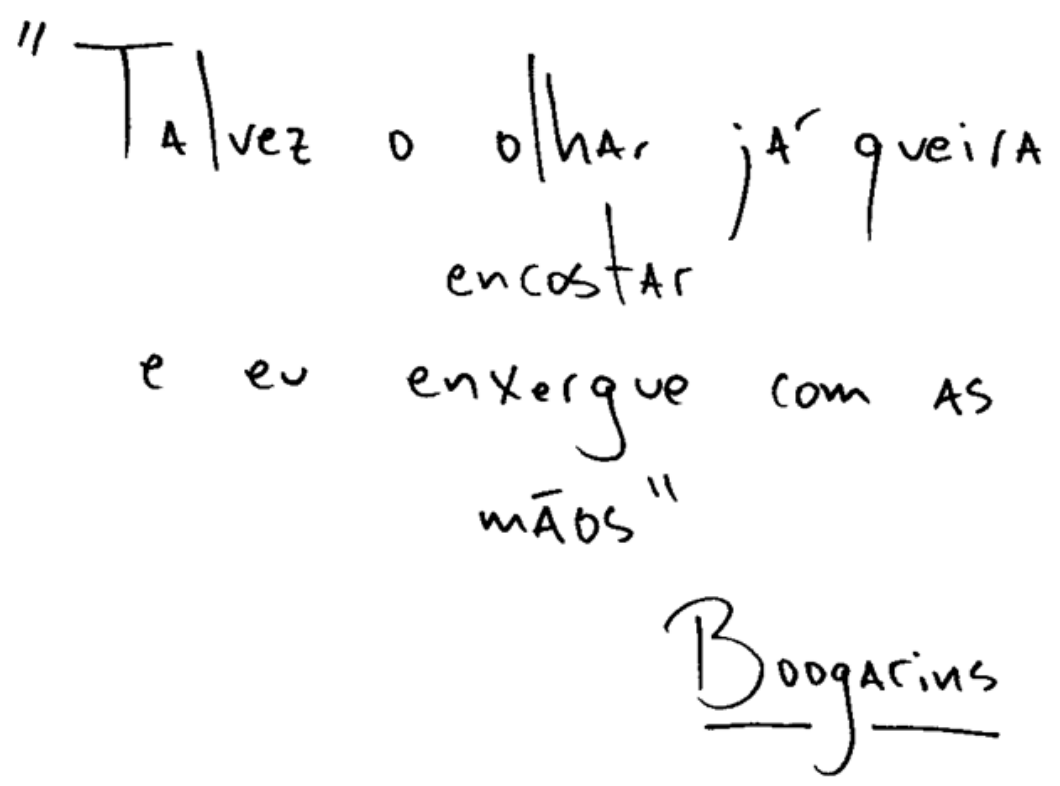


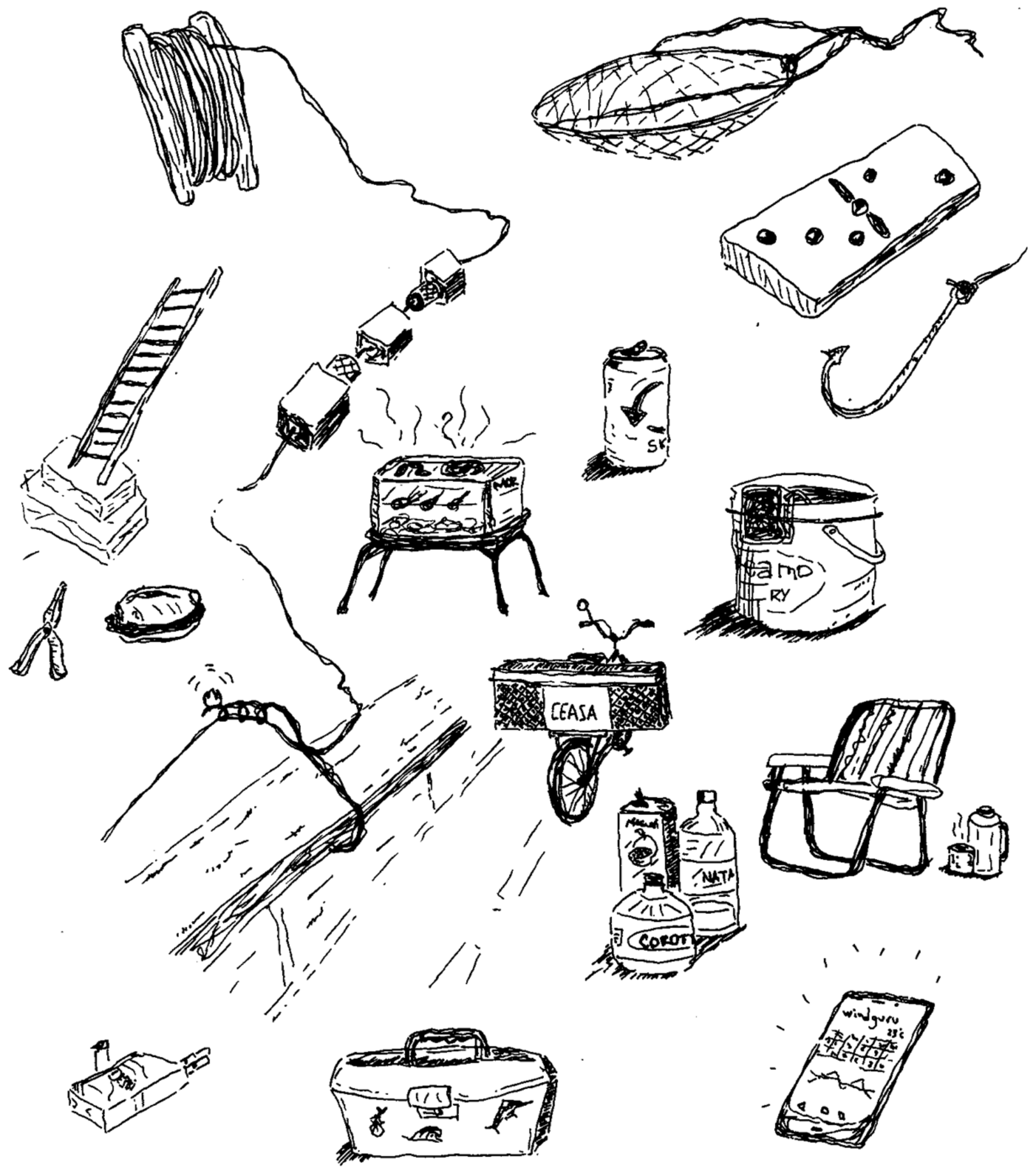




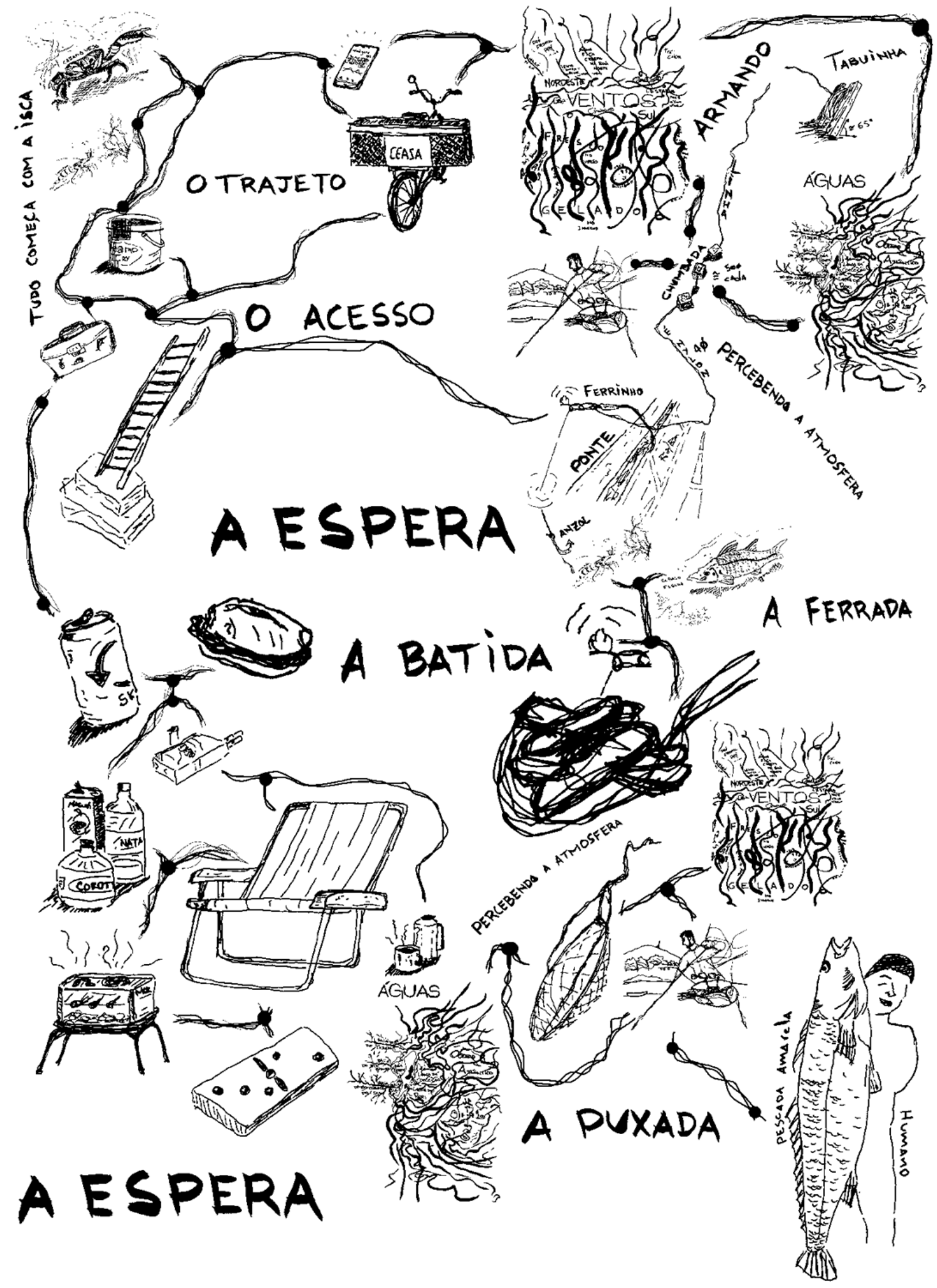


GOMES DE OLIVEIRA | Guia de relações multiespécies na Baía de Florianópolis - SC | 14

nĀo podem ser pensados 1 sequer representados - separadamente.

Em coordenaç̃o coma in

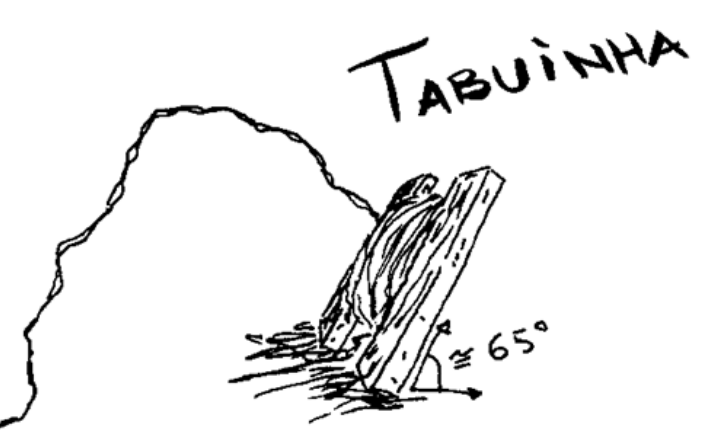

ferrinho, tabuinha ponte compóem a cadeia $\}^{4}$ pelos próprios pescadores. operatória da com tabuinha e ferrinho.

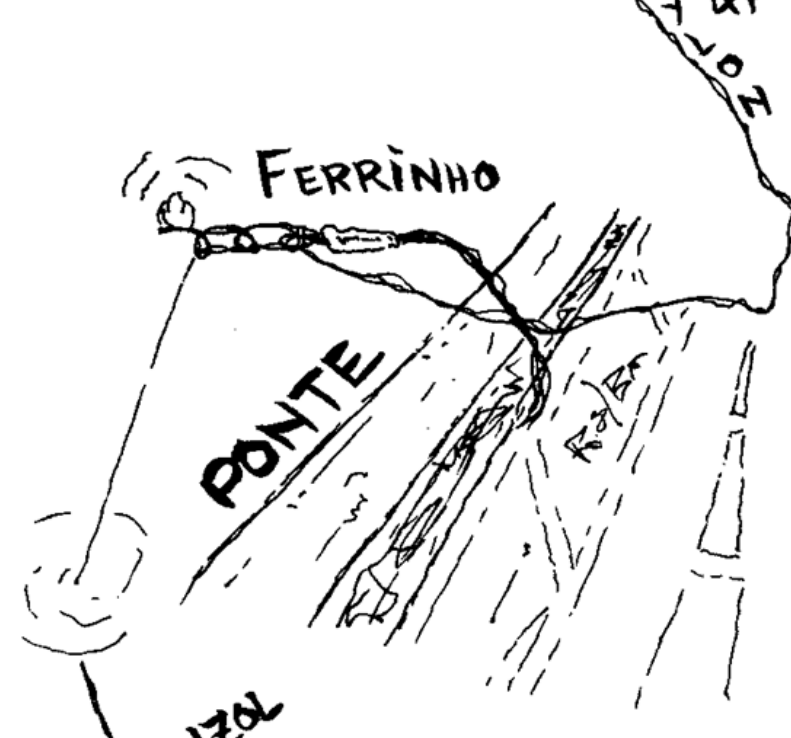

É uma "arte" de pesa por ser fruto de uma atividade criativa, desenvolvida, ao longo de décadas, por diversos pescadoses que perceberam que a ponte pode ser muito mais do que un objeto para a passagem.

Cadernos de Campo (São Paulo, online) | vol. 30, n. 1 | p.1-18 | USP 2021 


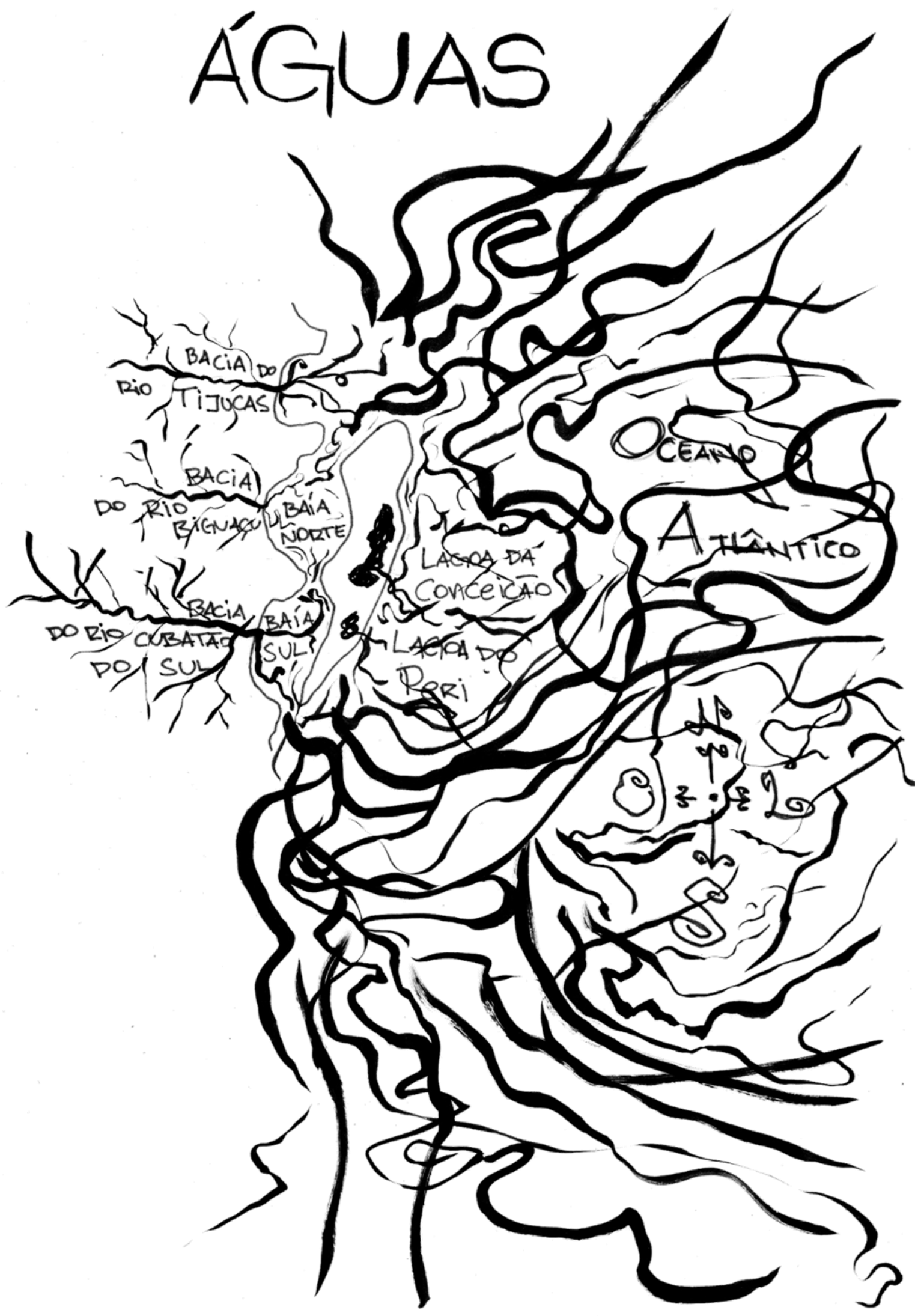

Cadernos de Campo (São Paulo, online) | vol. 30, n. 1 | p.1-18 | USP 2021 
GOMES DE OLIVEIRA | Guia de relações multiespécies na Baía de Florianópolis - SC | 16

"Cuidado que tá subindo

- ouro!", disse certa noite um pescador ao passar - viveiro de camarão para outro pescador que carregava os artefattos ao subir uma escada improvisada para acessar a VIVEIRO Colombo Machado Salles.

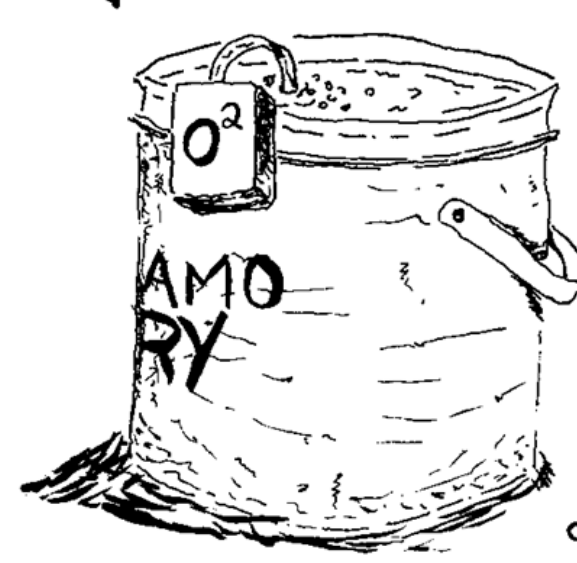

Normalmente feito com um baldinho de gordura vegetal reaproveitado, com um motorzinho de oximater vivos os camaróes que servem de isea viva or comida fresca - para pesca de corvinas, burriquetes, pescadas e, principalmente, robalos.

Cadernos de Campo (São Paulo, online) | vol. 30, n. 1 | p.1-18 | USP 2021 
GOMES DE OLIVEIRA | Guia de relações multiespécies na Baía de Florianópolis - SC | 17

"É o que eu sempre digo:

"ñ̄o vem pra ponte sem o jereré".

A frase resume bem a importáncia Lesse artefato pra pesca na
ponte - principalmen-
te se vocé espera
sair de lá com burriquete. puxar o peixe até a passarela, a uma altura de cerca de $3 \phi$ metros, e fazer isso sem rasgara boca de um peixe de mais de $10 \mathrm{~kg}$ só pelo Anzol seria improvável.

Cadernos de Campo (São Paulo, online) | vol. 30, n. 1 | p.1-18 | USP 2021 


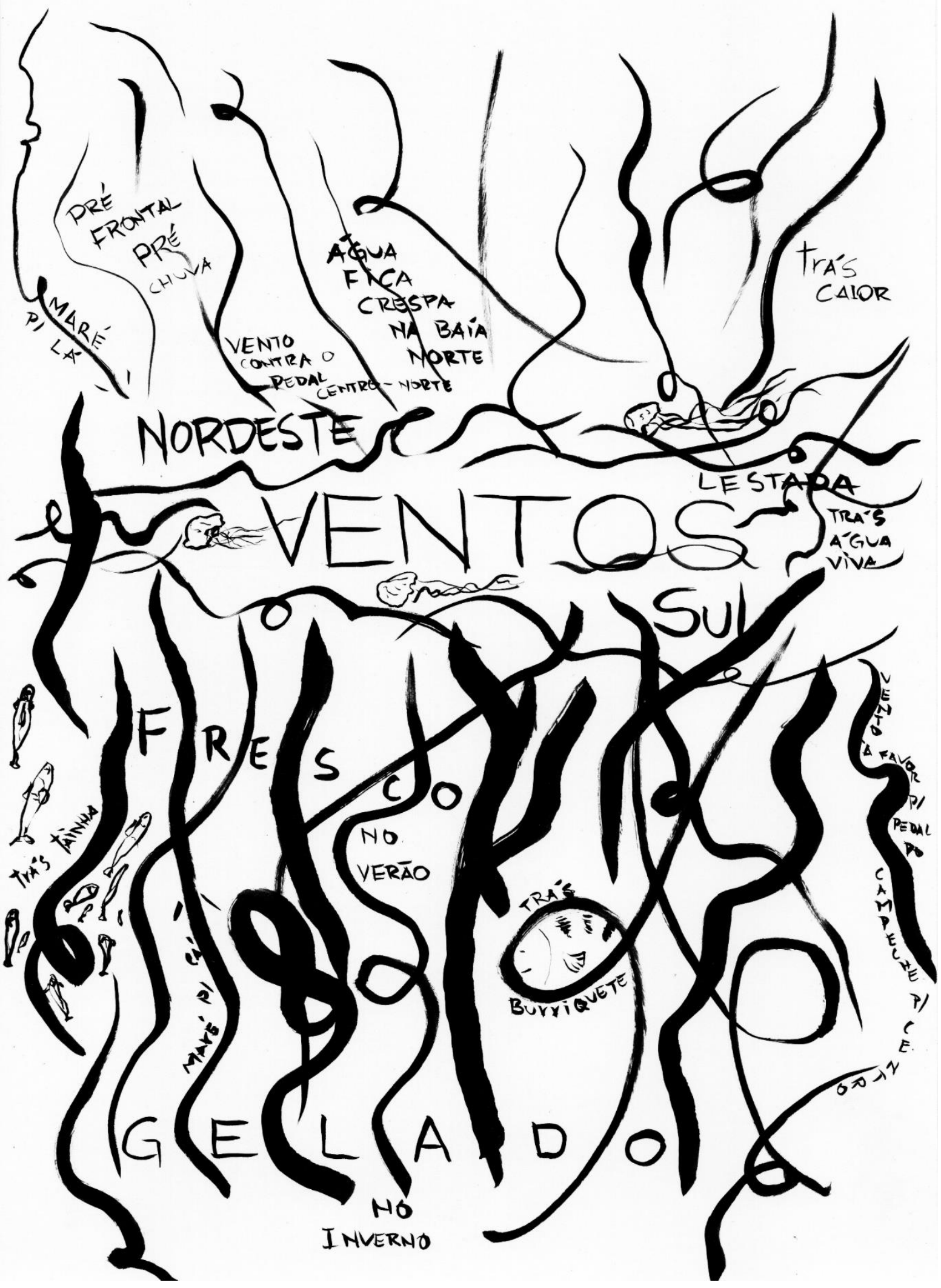

